\section{Vulnerability and self-perceived health status among light and heavy smokers: the relationship to short-term fear appeal tobacco control messages}

\author{
Vulnerabilidade e percepção de saúde auto- \\ referida entre fumantes leves e pesados: a relação \\ com mensagens anti-fumo voltadas para o apelo
} ao medo imediato

\author{
${ }_{1}$ Coordenação de Prevenção e \\ Vigilância, Instituto Nacional \\ de Câncer, Rio de Janeiro, \\ Brasil. \\ 2 Escola Nacional de Saúde \\ Pública Sergio Arouca, \\ Fundação Oswaldo Cruz, \\ Rio de Janeiro, Brasil. \\ Correspondence \\ A. Szklo \\ Divisão de Epidemiologia, \\ Coordenação de Prevenção e \\ Vigilância, Instituto Nacional \\ de Câncer. \\ Rua dos Inválidos 212, 3 o \\ andar, Rio de Janeiro, $R J$ \\ 20231-020, Brasil \\ aszklo@inca.gov.br
}

\section{Abstract}

It is important to stimulate smokers to acquire some level of risk perception associated with their current behavior in order to motivate smoking cessation. The present article attempts to understand how the content of short-term fear appeal government tobacco messages may interact with different levels of daily cigarette consumption in order to affect smokers' vulnerabilities, expressed by self-perceived health status. A Poisson model was used to estimate the prevalence ratio of fair or poor self-perceived health status (FPHS) according to daily cigarette consumption. We also calculated the proportions of smokers who stated that selected health warning pictures on cigarette packets encourage people to quit smoking, stratified by self-perceived health status and daily cigarette consumption. The proportion of smokers with FPHS was 25\% higher among those who smoked $>20$ cigarettes/day $(p=0.01)$. Among smokers with FPHS, heavy smokers showed the highest proportions of responses in favor of selected warning pictures most closely related to losses in ordinary daily living, such as shortness of breath and being bothered by cigarette addiction. Short-term loss-framed tobacco control messages seem to have raised awareness of vulnerability among heavier smokers.

Smoking Cessation; Tobacco Control Campaigns; Risk Assessment
André Salem Szklo ${ }^{1}$

Evandro Silva Freire Coutinho 2

\section{Introduction}

The degree of optimism, i.e. individuals' belief in their invulnerability, may inform the degree of relevance (perception) they ascribe to a given issue, as well as the level of control of their fear 1 . Self-esteem, in turn, is an element that can further accentuate the low sensitivity ascribed to the negative effects related to given risk behaviors 2 .

It is important to encourage smokers to acquire some level of risk perception associated with their current behavior in order to motivate smoking cessation $3,4,5$. One of the strategies that can be used is to transmit a message or image that expresses either loss/harm associated with maintenance of current behavior or gains to be obtained if individuals achieve some change in their current harmful behavior 6 .

Some authors have suggested that the presence of an impending loss has a strong impact on risk perception, indicating individuals' preference for avoiding losses rather than obtaining gains 7,8 . However, individuals who have smoked for a long time or who smoke more cigarettes per day and who thus begin to feel the effects of this behavior on their health (i.e. individuals who are more susceptible or vulnerable) may be more sensitive to daily-loss fear appeal messages than young individuals who are out to discover life and always obtain, for example, new and greater gains $9,10,11,12$. In fact, some authors have found that positive messages linked to the logic of pos- 
sible gains and lower stimulus for fear may find a more fertile ground for interaction with more optimistic and "invulnerable" individuals 13 , such as less nicotine dependent smokers 14,15,16.

The more smokers feel threatened by their given risk behavior, the more they tend to establish a close relationship between short-term risk perception and poor self-perceived health status. This connection is based on a subjective feeling that some unwanted state exists 17 .

The present article attempted to assess how the content of short-term fear appeal tobacco messages may interact with different levels of cigarette consumption in smokers. We hypothesized that, the greater the addiction in smokers, the greater the likelihood that they will move through different stages of processing of feararousing communications, resulting in a change in self-perceived health status. Our report is based on data from a population-based household survey on risk behaviors and self-reported morbidity, conducted in Brazil from 2002 to 2004.

\section{Methodology}

The household population-based survey on risk behaviors and self-reported morbidity for noncommunicable diseases was conducted from 2002 to 2004. The target population consisted of individuals aged 15 and older, residing in Brazil's Federal District (Brasilia) and 17 state capitals. A two-stage self-weighted sampling model was used. The primary sampling units were census tracts and the secondary, households. Further details are provided elsewhere 18 .

The total number of regular daily smokers - having smoked at least 100 cigarettes in life and being a current daily smoker - who answered all the questions on health status and cigarette consumption was $4,083(99.7 \%$ of the 4,095 identified). The overall non-response was $10.3 \%$, with a between-city variation of $3.5 \%$ to $15.9 \%$.

The question "Compared to persons of your age, in general, how do you rate your own health status?" was used to assess self-perceived health status. This question, used in the WHO Standard Risk Factor Questionnaire and Behavioral Risk Factor Surveillance System (BRFSS/Centers for Disease Control and Prevention), was asked directly and offered five responses: excellent, very good, good, fair, and poor. Due to the low proportion of smokers with poor self-perceived health status, we compared the alternatives fair or poor with the sum of all other possible answers. The smoker's degree of addiction was measured by mean daily cigarette consumption, as defined by the question "On average, how many cigarettes do you smoke per day?" and was categorized as 1 to 20 (light) versus 21 or more cigarettes (heavy) per day. This cut-off point was based on results from previous research suggesting that smokers satisfy their dependence-related craving with around 20 cigarettes per day 19 .

The following potential confounding variables were included in the model aiming at assessing the association between self-perceived health status and daily cigarette consumption: sex, age (15-24, 25-34, 35-44, 45-54 and 55 and older), schooling (fewer than vs. equal or more than eight years), heavy alcohol consumption, self-reported history of diagnosis of depression, and geographic area of residence.

Heavy alcohol consumption was defined as mean consumption, in the previous 30 days, of more than 2 doses a day for men and 1 dose a day for women 20 . Self-reported history of diagnosis of depression was assessed by the response "yes" or "no" to the question "Has any physician ever told you that you have or have had depression?". Geographic area was classified according to the five major regions of Brazil: North [Manaus (Amazonas State), Belém (Pará), and Palmas (Tocantins)], Northeast [São Luís (Maranhão), Fortaleza (Ceará), Natal (Rio Grande do Norte), Recife (Pernambuco), João Pessoa (Paraíba), and Aracaju (Sergipe)]; Southeast [Vitória (Espírito Santo), Belo Horizonte (Minas Gerais), Rio de Janeiro, and São Paulo]; Central West (Federal District and Campo Grande (Mato Grosso do Sul)]; and South [Florianópolis (Santa Catarina), Curitiba (Paraná), and Porto Alegre (Rio Grande do Sul)].

The impact of prevailing tobacco control message on smokers was assessed by showing a card to the participants with the different health warning pictures appearing on cigarette packets at the time of interview. After showing the card, the interviewer asked the following question for each picture: "Do you think this health warning picture on cigarette packets encourages people to quit smoking?". For cost reason, we had to use two questionnaires for different samples (short vs. complete) of the previously cited National Household Survey. The question on health warnings was not included in the short version and, thus, was only applied to a systematic sample of $50 \%$ of the initially selected smokers aged 25 and above.

Among the eight fear appeal health warning pictures selected by the National Tobacco Control Program to be printed on cigarette packs in 2002, the present article dealt with two themes mainly related to the short-term consequences of tobacco smoking: shortness of breath -"smokers are always short of breath" 
and nicotine dependence, "nicotine is a drug and leads to addiction". Moreover, the health warning related to lung cancer "smoking causes lung cancer", although addressing a longer term outcome, was also included due to the widely publicized impact of smoking on lung cancer risk. Two health warning pictures that address the themes of heart disease and mouth cancer were not included as they would have represented longer term outcomes while not perceived as being causally associated with tobacco to the same extent as lung cancer. Finally, the themes of sexual impotence, miscarriage and smoking during pregnancy, although related to shortterm consequences, were not used as they were considered to be gender-specific.

\section{Data analysis}

Stata software, version 9.0 (Stata Corp., College Station, USA) was used for processing of variables and data analysis. The analyses used the application's svy command to deal adequately with the cluster sampling structure and allow the incorporation of the expansion fractions in the analyses.

Distributions were inspected by sex, age, schooling, heavy alcohol consumption, self-reported history of diagnosis of depression, and geographic area of residence. Proportions of individuals who rated their health status as fair or poor were estimated according to smokers' mean daily cigarette consumption. A Poisson multivariate regression model was then used to estimate the prevalence ratio and its $95 \%$ confidence interval of fair or poor self-perceived health status adjusted by sex, age, schooling, heavy alcohol consumption, self-reported history of depression, and geographic area of residence. These potential confounding variables were extracted from the literature and also identified using a "change-in-estimate" method 21. Variable selection was approached by direct estimation of the degree of confounding produced by each variable. It was based on at least a $5 \%$ change in point prevalence ratio when the variable was entered in the crude Poisson model.

The study also estimated the proportions of individuals who stated that the selected warning picture used by the National Tobacco Control Program encourages people to quit smoking, according to smokers' mean daily cigarette consumption, stratified by self-perceived health status. After that, a Poisson regression model was used to calculate crude and adjusted prevalence ratios (and respective $p$ values) of smokers who stated that the selected health warning encour- ages people to quit smoking. A two-way interaction term was also added to the model in order to assess interaction between self-perceived health status and cigarette consumption.

\section{Results}

Approximately $50 \%$ of the study population consisted of male smokers and some $40 \%$ of the selected smokers were aged 15 to 34 years. About $55 \%$ had complete primary schooling and 1 in 5 smokers reported heavy alcohol consumption or a self-reported history of diagnosis of depression. All Brazilian regions were represented, and the highest proportion of smokers was observed in the Southeast. Close to $90 \%$ of smokers reported an average of up to 20 cigarettes per day, and approximately one in three rated their health status as fair or poor. There were no statistically significant differences between the sample of smokers who answered questions pertaining to health warning messages and the whole sample included in the survey with regard to the variables considered in Table 1.

The proportion of smokers who rated their health status as fair or poor was $44 \%$ higher among those who smoked more than 20 cigarettes per day (Table 2). After controlling for the effects of sex, age, schooling, heavy alcohol consumption, self-reported history of diagnosis of depression, and geographic area, heavy smoking was associated with a worse self-perceived health status. The prevalence of fair or poor self-perceived health status was $25 \%$ higher among those who smoked from 21 to 80 cigarettes per day than that observed among those who smoked 20 cigarettes or less per day.

In Table 3, comparing smokers who smoked up to 20 cigarettes per day with those who smoked 21 or more cigarettes per day, the adjusted proportion of individuals who stated that the health warning pictures from the National Tobacco Control Program related to shortness of breath and the association between nicotine and addiction encourage people to quit smoking was higher among heavier smokers, with statistically significant adjusted prevalence ratios for both categories of self-perceived health status. The question related to the specific health warning picture on lung cancer obtained over $50 \%$ of "yes" responses among both light and heavy smokers and in both categories of self-perceived health status and age groups.

No heterogeneity shown in Table 3 was found to be statistically significant, except for the interaction between self-perceived health status and cigarette consumption among smokers who gave 
Distributions of selected variables in all daily smokers and in the sample who answered questions on health warning messages.

\begin{tabular}{|c|c|c|c|c|}
\hline \multirow[t]{3}{*}{ Variable } & \multicolumn{4}{|c|}{ Daily smokers } \\
\hline & \multirow{2}{*}{\multicolumn{2}{|c|}{ All population }} & \multirow{2}{*}{\multicolumn{2}{|c|}{$\begin{array}{l}\text { Sample who answered questions or } \\
\text { health warning messages }\end{array}$}} \\
\hline & & & & \\
\hline \multicolumn{5}{|l|}{ Sex } \\
\hline Male & 2,183 & 51.4 & 1,587 & 51.9 \\
\hline Female & 1,912 & 48.6 & 1,333 & 48.1 \\
\hline \multicolumn{5}{|l|}{ Age (years) } \\
\hline $15-24$ & 727 & 16.6 & 727 & 16.7 \\
\hline $25-34$ & 893 & 20.1 & 573 & 19.9 \\
\hline $35-44$ & 1,127 & 28.1 & 733 & 28.3 \\
\hline $45-54$ & 813 & 21.5 & 552 & 21.9 \\
\hline $55+$ & 535 & 13.8 & 335 & 13.3 \\
\hline \multicolumn{5}{|l|}{ Schooling } \\
\hline Incomplete primary & 1,984 & 46.4 & 1,396 & 46.4 \\
\hline Complete primary & 2,038 & 53.6 & 1,473 & 53.6 \\
\hline \multicolumn{5}{|c|}{ Heavy alcohol consumption } \\
\hline Yes & 804 & 19.3 & 590 & 18.9 \\
\hline No & 3,125 & 80.7 & 2,206 & 81.1 \\
\hline \multicolumn{5}{|c|}{ Self-reported history of diagnosis of depression } \\
\hline Yes & 758 & 19.6 & 529 & 19.9 \\
\hline No & 3,334 & 80.4 & 2,390 & 80.1 \\
\hline \multicolumn{5}{|c|}{ Geographic area of residence } \\
\hline North & 559 & 5.8 & 399 & 5.7 \\
\hline Northeast & 1,054 & 15.7 & 828 & 15.8 \\
\hline Central West & 389 & 6.9 & 260 & 6.5 \\
\hline Southeast & 1,161 & 60.2 & 784 & 59.9 \\
\hline South & 932 & 11.4 & 649 & 11.9 \\
\hline \multicolumn{5}{|c|}{ Mean cigarette consumption per day } \\
\hline $21+$ & 404 & 10.6 & 287 & 10.6 \\
\hline $1-20$ & 3,684 & 89.4 & 2,628 & 89.4 \\
\hline \multicolumn{5}{|c|}{ Self-perceived health status } \\
\hline Excellent & 513 & 14.0 & 356 & 14.0 \\
\hline Very good & 537 & 13.8 & 386 & 14.0 \\
\hline Good & 1,638 & 38.6 & 1,146 & 37.9 \\
\hline Fair & 1,285 & 31.4 & 957 & 32.8 \\
\hline Poor & 117 & 2.9 & 72 & 2.5 \\
\hline
\end{tabular}

* The total number of smokers was 4,095; 73 failed to inform their level of schooling, 166 failed to inform their alcohol consumption, 3 lacked information on self-reported presence/absence of depression, 7 failed to provide information on the mean number of cigarettes smoked per day, and 5 did not inform their self-perceived health status;

** Expanded N, considering the census tract as the primary sampling unit and expansion factor: men $(1,841,642)$, women $(1,743,625), 15-24$ years $(595,223)$, $25-34(720,309), 35-44(1,004,349), 45-54(769,866), 55+(495,520)$, incomplete primary schooling $(1,879,987)$, complete primary schooling $(1,626,321)$, heavy alcohol consumption $(666,979)$, light/moderate or absent alcohol consumption $(2,781,631)$, self-reported presence of depression $(701,126)$, self-reported absence of depression $(2,882,371)$, resident in the North $(207,721)$, Northeast $(564,356)$, Central West $(246,836)$, Southeast $(2,158,111)$, South $(408,243)$, 21 or more cigarettes per day $(379,213)$, fewer than 21 cigarettes per day $(3,201,818)$, self-perceived health status excellent $(499,648)$, very good $(494,431)$, good $(1,382,765)$, fair $(1,101,766)$, poor $(103,892)$;

*** Percentages calculated with the census tract as the primary sampling unit and expansion factor;

\# The total number of smokers was 2,920; 51 failed to inform their level of schooling, 124 failed to inform their alcohol consumption, 1 lacked information on self-reported history of depression, 5 failed to provide information on the mean number of cigarettes smoked per day, and 3 did not inform their self-perceived health status;

\#\# Expanded N, considering the census tract as the primary sampling unit and expansion factor: men $(1,850,652)$, women $(1,712,986), 15-24$ years $(593,616)$, 25-34 (707,987), 35-44 (1,007,451), 45-54 (781,598), 55+ $(472,986)$, incomplete primary schooling $(1,872,010)$, complete primary schooling $(1,619,641)$, heavy alcohol consumption $(647,166)$, light/moderate or absent alcohol consumption $(2,784,265)$, self-reported presence of depression $(709,819)$, selfreported absence of depression $(2,853,337)$, resident in the North $(203,721)$, Northeast $(563,858)$, Central West $(232,708)$, Southeast $(2,129,070)$, South $(434,281), 21$ or more cigarettes per day $(378,172)$, fewer than 21 cigarettes per day $(3,180,035)$, self-perceived health status excellent $(498,814)$, very good $(497,564)$, good $(1,350,015)$, fair $(1,126,714)$, poor $(89,054)$. 
Crude and adjusted prevalence ratios (PR) * for fair or poor self-perceived health status according to mean daily cigarette consumption.

\begin{tabular}{lccc}
\hline Cigarettes/day & Prevalence (\%) & Crude PR & Adjusted PR \\
\hline $1-20$ & 32.6 & 1.0 & 1.0 \\
$21-80$ & 46.9 & $1.44(1.15,1.54)$ & $1.25(1.10,1.49)$ \\
\hline
\end{tabular}

* Multivariate regression analysis using the Poisson model adjusted by sex, age, schooling, heavy alcohol consumption, selfreported history of diagnosis of depression, and geographic area of residence, with the census tract as the primary sampling unit and expansion factor; $95 \%$ confidence intervals.

Table 3

Crude (CPR) and adjusted (APR) prevalence (PR) ratios * for smokers who stated that selected health warning pictures ** encourage people to quit, according to mean daily cigarette consumption, stratified by self-perceived health status.

\begin{tabular}{|c|c|c|c|c|c|c|c|c|c|}
\hline \multirow[t]{3}{*}{ Cigarettes/day } & \multicolumn{9}{|c|}{ Selected health warning } \\
\hline & \multicolumn{3}{|c|}{ Shortness of breath $* \star \star$} & \multicolumn{3}{|c|}{ Nicotine addiction \# } & \multicolumn{3}{|c|}{ Lung cancer \#\# } \\
\hline & PR (\%) & CPR & APR \#\#\# & PR (\%) & CPR & APR \#\#\# & PR (\%) & CPR & APR \#\# \\
\hline \multicolumn{10}{|c|}{ Excellent/Very good/Good § } \\
\hline $1-20$ & 26.8 & 1.0 & 1.0 & 29.8 & 1.0 & 1.0 & 79.7 & 1.0 & 1.0 \\
\hline $21+$ & 43.6 & $1.63 \S \S$ & $1.41 \S \S$ & 47.2 & $1.58 \S \S$ & $1.39 \S \S$ & 86.7 & 1.08 & $1.17 \S \S \S$ \\
\hline \multicolumn{10}{|l|}{ Fair/poor § } \\
\hline $1-20$ & 28.8 & 1.0 & 1.0 & 26.9 & 1.0 & 1.0 & 75.7 & 1.0 & 1.0 \\
\hline $21+$ & 35.5 & $1.23 \S \S$ & $1.25 \S \S$ & 34.0 & $1.26 \S \S$ & $1.27 \S \S$ & 54.5 & $0.72 \S \S$ & $0.70 \S \S$ \\
\hline
\end{tabular}

* Poisson regression model was used to estimate crude and adjusted (by age, sex, schooling, heavy alcohol consumption, self-reported history of depression, and geographic area of residence) prevalence ratios of smokers who stated that selected health warning pictures encourages people to quit smoking, according to mean daily cigarette consumption, stratified by self-perceived health status;

** Printed on cigarette packs sold in Brazil during the period in which the survey was conducted. Question addressed to a sub-sample of the initial population of smokers;

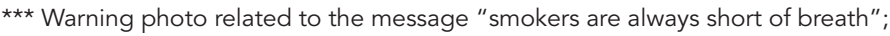

\# Warning photo related to the message "nicotine is a drug and causes addiction";

\#\# Warning photo related to the message "smoking causes lung cancer";

\#\#\# Regarding answers to health warning on lung cancer, the interaction between self-perceived health status and cigarette consumption was statistically significant $(p=0.045)$. No other heterogeneity shown in table 3 was found to be statistically significant;

$\S$ Self-perceived health status;

$\S \S p$ value $\leq 0.05$;

$\S \S \S$ value $\leq 0.10$

"yes" responses to the question related to health warning on lung cancer $(\mathrm{p}=0.045)$.

In order to evaluate a possible rounding bias (to 20 cigarettes), the analyses in Table 2 and Table 3 were redone with a new dichotomous variable with categories defined as 1 to 19 versus 20 or more cigarettes per day; the previously observed effects were attenuated, indicating that this bias was probably greater among lighter smokers, which would justify the classification used in this article.

\section{Discussion}

In our study, we showed that, compared with light smokers, a higher proportion of heavy smokers rated their own health status as fair or poor, which is widely consistent with the literature 22,23

The strategy used by the Brazilian National Tobacco Control Program, based on publicizing cigarettes' harmful effects, began in the mid1980s, while aversive health warning pictures began to be printed on cigarette packets in 200224 . 
The results presented in the current article thus show the relationship between smokers' cigarette consumption and the above-mentioned awareness-raising measures, based on two different situations: (i) to perceive a more distant or almost nonexistent individual risk while reacting on the importance of anti-tobacco messages to encourage smokers in general to quit smoking, and (ii) to establish a closer relationship between those messages and fair or poor self-perceived health status (proxy to perception that the risk is more immediate). The former is a phenomenon known as "optimistic bias" 25,26,27,28 and can be observed in Table 3 among smokers who did not rate their health status as fair or poor, i.e., those who probably were not stimulated to perceive an impending risk, but who possibly considered that the health warning pictures were relevant and could help other smokers (who probably experienced that problem) to seek help.

Specifically regarding tobacco control messages involving warning pictures related to more objective issues, i.e., those more subject to vulnerabilities and daily losses like shortness of breath and being bothered by cigarette addiction, which apply to both male and female, and younger and older smokers 14,29, there was a greater awareness of these issues among heavy smokers. This awareness was based on either a perception of a distant (but existent) risk - among heavy smokers with at least good self-perceived health status - or the identification with a current and relevant personal problem - among heavy smokers with fair or poor self-perceived health status. No interaction (i.e. heterogeneity) was observed between self-perceived health status and mean daily cigarette consumption with regard to "yes" responses to questions related to shortness of breath or nicotine addiction. These findings emphasize that the process of complete behavior change (i.e., smoking cessation) may not be immediate 3 because individuals initially appraise the threat conveyed by the message and start thinking about the pros and cons related to smoking behavior, either for themselves or others. The more individuals believe they are susceptible to a serious threat, the more they process the message further. Obviously, depending on the individual's life experience, some objective issues may be more relevant than others (i.e., nicotine dependence and young smokers, women and smoking during pregnancy).

Lower sensitivity to the strong presence of daily loss or harm observed among light smokers reinforces their self-esteem and belief in invulnerability. As already noted by several authors, stimuli provided by gain-framed messages would have probably motivated less addicted smokers to start thinking about changing current behavior by trading something that provides pleasure ("gain") for something that gives just as much or more pleasure at a lower cost or risk 12,14.

The lung cancer issue, which has been highly publicized over the years, was apparently relevant for all smokers, while the lower impact of the health warning picture among heavy smokers with worse self-perceived health status may indicate a greater "defensive avoidance" on their part, i.e., a greater tendency to avoid a more detailed and systematic analysis of the issue, rather choosing to work with preconception in favor of the smoking behavior in order to succeed in controlling their growing fear 30,31 . These results are consistent with the stage model proposed by De Hoog et al. ${ }^{32}$. It is proposed that when a risk is depicted as extremely severe (e.g. death by lung cancer), even if individuals do not feel personally vulnerable, they assume to invest some effort in processing the contents of communication. When individuals move to another stage of message processing and start feeling that some unwanted personal health state exists, the more impending and severe the threat is, the more it arouses defense motivation. Analyses presented here suggest that heavy smokers with fair or poor self-perceived health status may be located at later stages of fear-appeal messages processing than the corresponding light smokers.

\section{Study limitations}

The association observed between mean number of cigarettes per day and self-perceived health status may involve other elements of vulnerability in addition to those contemplated by the confounders used in the analyses. Moreover, the cross-sectional nature of the study prevents the assessment of temporality.

In the current study, information was self-reported, and thus measurement error may have occurred. Loss of information from individuals selected for the household survey may have influenced the results. However, assuming that the individuals who were lost due to refusal had the same smoking prevalence and behavioral characteristics as those included in the study, they would have represented an increase of only $2 \%$ in smoking population used in the analysis $(10 \%$ of individual refusal multiplied by $19 \%$ of estimated smoking prevalence). Another potential limitation is that grouping the fair and poor self-perceived health status groups probably combined individuals with different morbidity profiles and risk behaviors. 
Interestingly, although smokers' risk perception is highly important for future behavior change $\mathrm{e}^{4,5,33}$, according to numerous studies, the real behavior change mechanisms still remain unknown for many contexts and situations. Milio ${ }^{34}$ suggested that individuals always choose the easiest attitude, with the lowest cost. The importance of tax increases on cigarettes (and consequently the increase in their price), highlighted by Hu et al. 35 , had a direct influence on cigarette consumption.

\section{Conclusions}

We have shown the independent association of mean cigarette consumption with fair or poor self-perceived health status, irrespective of age, sex, schooling, heavy alcohol consumption, selfreported history of diagnosis of depression, and place of residence. This result strengthened the relationship between messages used by the Brazilian National Tobacco Control Program, based on short-term fear and losses, and their impact

\section{Resumo}

É importante incentivar os fumantes a adquirir algum nível de percepção do risco associado ao seu comportamento atual, para motivá-los a parar de fumar. O artigo procura elucidar em que medida o conteúdo do apelo ao medo imediato contido em mensagens anti-fumo nas campanhas governamentais pode interagir com o consumo diário de cigarros, no sentido de afetar as vulnerabilidades dos fumantes, expressas pela percepção de saúde auto-referida. Um modelo de Poisson foi utilizado para estimar a razão de prevalências de percepção de saúde auto-referida regular ou ruim, segundo consumo diário de cigarros. Calculou-se também a proporção de fumantes que afirmou que mensagens anti-fumo impressas em maços de cigarros incentivam as pessoas a para de fumar, estratificada por percepção de saúde auto-referida e consumo diário de cigarros. A proporção de fumantes com percepção de saúde auto-referida regular ou ruim foi $25 \%$ maior entre aqueles que fumavam $>20$ cigarros/dia $(p=0,01)$. Entre fumantes com percepção de saúde auto-referida regular ou ruim, os fumantes pesados apresentaram as proporções mais elevadas de respostas em favor das mensagens anti-fumo mais identificadas com perdas na vida cotidiana, como falta de fôlego e sentir-se incomodado pela própria dependência em relação ao cigarro. Mensagens anti-fumo voltadas para perdas em curto prazo parecem ter aumentado a conscientização dos fumantes mais pesados em relação à sua própria vulnerabilidade.

Abandono do Hábito de Fumar; Campanhas para o Controle do Tabagismo; Medição de Risco on heavy smokers' vulnerability. An undesirable setting of harm to health and uncertainties associated with given purported risk behavior stimulated by the use of health warnings establishes, at the beginning, an appraisal of the severity of the threat. Then, heavy smokers move to a second appraisal which determines the close relationship between impending self-perceived risk and fair or poor self-perceived health status, suggesting that the components of fear-arousing strategies probably occur in a temporal sequence.

Communications elements related to daily losses, with their clear and focused message, appeared to be important for heavy smokers to see meaning in the information they received $36,37,38$. However, future studies should consider the population impact gain with different communication messages targeting smokers with different levels of cigarette consumption. Awareness-raising strategies with a wide population reach, such as through the mass media or using propaganda on cigarette packs have an important role in publicizing anti-tobacco interventions, strengthening the issue's personal relevance 39 .

\section{Contributors}

A. S. Szklo participated in the data analysis and as author in the preparation and elaboration of the article. E. S. F. Coutinho participated in the data analysis and as co-author in the preparation and elaboration of the article.

\section{Acknowledgements}

The Household Survey on Risk Behaviors and Reported Morbidity for Non-Communicable Diseases was financed by the Health Surveillance Secretariat of the Brazilian Ministry of Health with counterpart funds from the National Cancer Institute (INCA). We wish to thank the Fogarty International Center of the National Institutes of Health (USA) for supporting the research through grant no. R01-HL-73699. We would like to thank Dr. Valeska Figueiredo for her insightful comments in preparation of the manuscript. 


\section{References}

1. Slovic P. Perception of risk. Science 1987; 236: 280-5.

2. Gibbons FX, Eggleston TJ, Benthin AC. Cognitive reactions to smoking relapse: the reciprocal relation between dissonance and self-esteem. J Pers Soc Psychol 1997; 72:184-95.

3. Witte K, Allen M. A meta-analysis of fear appeals: implications for effective public health campaigns. Health Educ Behav 2000; 27:591-615.

4. Weinstein ND, Rothman AJ, Nicolich M. Use of correlational data to examine the effects of risk perceptions on precautionary behavior. Psychol Health 1998; 13:479-501.

5. Ward H, Mertens TE, Thomas C. Health seeking behaviour and the control of sexually transmitted disease. Health Policy Plan 1996; 12:19-28.

6. Brendl SM, Higgins ET, Lemm K. Sensitivity to varying gains and losses: the role of self-discrepancies and event framing. J Pers Soc Psychol 1995; 69:1028-51.

7. White MP, Pahl S, Buehner M, Haye A. Trust in risky messages: the role of prior attitudes. Risk Anal 2003; 23:717-26.

8. Rozin P, Rozman EB. Negativity bias, negativity dominance, and contagion. Pers Soc Psychol Rev 2001; 5:296-320.

9. Rothman AJ, Salovey P. Shaping perceptions to motivate healthy behavior: the role of message framing. Psychol Bull 1997; 121:3-19.

10. Strathman A, Gleicher F, Boninger DS, Edwards CS. The consideration of future consequences: weighin immediate and distant outcomes behavior. J Pers Soc Psychol 1994; 66:742-52.

11. Steward WT, Schneider TR, Pizarro J, Salovey P. Need for cognition moderates responses to framed smoking-cessation messages. J Appl Soc Psychol 2003; 33:2439-64.

12. Lyna P, McBride C, Samsa G, Pollak KI. Exploring the association between perceived risk of smoking and benefits to quitting: who does not see the link? Addict Behav 2002; 27:293-307.

13. Goldberg JH, Halpern-Felsher BL, Millstein SG. Beyond invulnerability: the importance of benefits in adolescents' decision to drink alcohol. Health Psychol 2002; 21:477-84.

14. Dalton MA, Sargent JD, Beach ML, Bernhardt AM, Stevens M. Positive and negative outcome expectations of smoking: implications for prevention. Prev Med 1999; 29:460-5.

15. Piko BF, Bak J, Gibbons FX. Prototype perception and smoking: are negative or positive social images more important in adolescence? Addict Behav 2007; 32: 1728-32.

16. Schneider TR, Salovey P, Pallonen U, Mundorf N, Smith NF, Steward WT. Visual and auditory message framing effects on tobacco smoking. J Appl Soc Psychol 2001; 31:667-82.

17. Becker MH, Janz NK. Behavioral science perspectives on health hazard/health risk appraisal. Health Serv Res 1987; 22:537-51.
18. Coordenação de Prevenção e Vigilância, Instituto Nacional de Câncer. Inquérito domiciliar sobre comportamentos de risco e morbidade referida de doenças e agravos não-transmissíveis: Brasil, 15 capitais e Distrito Federal, 2002-2003. http://www. inca.gov.br/inquerito/ (accessed on 01/Oct/2008).

19. Figueiredo V, Szklo M, Szklo AS, Benowitz N, Lozana JA, Casado L, et al. Determinants of salivary cotinine level: a population-based study in Brazil. Rev Saúde Pública 2007; 41:954-62.

20. World Cancer Research Fund/American Institute for Cancer Research. Food, nutrition, physical activity, and the prevention of cancer: a global perspective. Washington DC: American Institute for Cancer Research; 2007.

21. Greenland S. Modeling and variable selection in epidemiologic analysis. Am J Public Health 1989; 79:340-9.

22. Heilingenstein E, Smith SS. Smoking and mental health problems in treatment-seeking university students. Nicotine Tob Res 2006; 8:519-23.

23. Wilson D, Parsons J, Wakefield M. The health-related quality-of-life of never smokers, ex-smokers, and light, moderate, and heavy smokers. Prev Med 1999; 29:139-44.

24. Cavalcante, T. The Brazilian experience with tobacco control policies. Salud Pública Méx 2004; 46:549-58.

25. Moran S, Glazier G, Armstrong K. Women smokers' perceptions of smoking-related health risks. Journal Womens Health 2003; 12:363-71.

26. Whalen CK, Henker B, O'Neil R, Hollingshead J, Holman A, Moore B. Optimism in children's judgements of health and environmental risks. Health Psychol 1994; 13:319-25.

27. van Hanswijck de Jonge L, Gormley M. Responses to positive and negative smoking-related images: effects of current smoking status and degree of smoking addiction. Addict Behav 2005; 30 : 1587-91.

28. van der Velde FW, Hooykaas C, van der Joop P. Risk perception and behavior: pessimism, realism, and optimism about AIDS-related health behavior. Psychol Health 1992; 6:23-38.

29. Weinstein ND, Slovic P, Gibson G. Accuracy and optimism in smokers' beliefs about quitting. Nicotine Tob Res 2004; 6:375-80.

30. Kleinjan M, van den Eijnden RJJM, Dijkstra A, Brug J, Engels RCME. Excuses to continue smoking: the role of disengagement beliefs in smoking cessation. Addict Behav 2006; 31: 2223-37.

31. Zuckerman A, Chaiken S. A heuristic-systematic processing analysis of the effectiveness of product warning labels. Psychology and Marketing 1998; 15:621-42.

32. Hoog N, Stroebe W, Wit JBF. The impact of fear appeals on the processing and acceptance of action recommendations. Pers Soc Psychol Bull 2005; 31:24-33.

33. Tessaro I, Lyna PR, Rimer BK, Heisler J, WoodsPowell CT, Yarnall KSH, et al. Readiness to change smoking behavior in a community health center population. J Community Health 1997; 22:15-31. 
34. Milio N. A framework for prevention: changing health-damaging to health-generating life patterns. Am J Public Health 1976; 66:435-9.

35. Hu T, Sung H, Keelr TE. Reducing cigarette consumption in California: tobacco taxes vs. an anti-smoking media campaign. Am J Public Health 1995; 85:1218-22.

36. Montazeri A, McEwen J. Effective communication: perception of two anti-smoking advertisements. Patient Educ Couns 1997; 30:29-35.

37. Hammond D, Fong GT, McDonald PW, Cameron R, Brown KS. Impact of the graphic Canadian warning labels on adult smoking behaviour. Tob Control 2003; 12:391-5.
38. O'Hegarty M, Pederson LL, Nelson DE, Mowery P, Gable JM, Wortley P. Reactions of young adult smokers to warning labels on cigarette packages. Am J Prev Med 2007; 30:467-73.

39. Portillo F, Antonanzas F. Information disclosure and smoking risk perceptions. Potential shortterm impact on Spanish students of the new European Union directive on tobacco products. Eur J Public Health 2002; 12:295-301.

Submitted on $09 /$ Oct $/ 2008$

Approved on 29/Dec/2008 